\title{
Ground-based observations of solar UV radiation at Tokyo, Brazil and Chile
}

H. Nozawa, H. Yamamoto (Rikkyo Univ.), K. Makita (Takusyoku Univ.), N. J. Schuch (INPE), D. K. Pinheiro, S. Carbone (Fed. Univ. Santa Maria), A. J. Foppiano (Univ. Concepcion), and R. M. Mac-Mahon (Univ. Magallanes)

Copyright 2005, SBGf - Sociedade Brasileira de Geofísica

This paper was prepared for presentation at the $9^{\text {th }}$ International Congress of the Brazilian Geophysical Society held in Salvador, Brazil, 11-14 September 2005

Contents of this paper were reviewed by the Technical Committee of the $9^{\text {th }}$ International Congress of the Brazilian Geophysical Society. Ideas and concepts of the text are authors' responsibility and do not necessarily represent any position of the SBGf, its officers or members. Electronic reproduction or storage of any part of this commercial purposes without the written consent of the Brazilian Geophysical Society is prohibited.

\section{Abstract}

In this paper, we show some results of ground-based observations of solar ultraviolet (UV) radiations using UV radiometers and spectroradiometers. Our observations have been carried out at lkebukuro, Japan and São Martinho, Brazil since 2002. Variation in flux ratio of UV-B to UV-A showed clear anti-correlation with that of effective ozone. As a result of functional fitting, exponential relations between the ratio and effective ozone were obtained. We are going to investigate long-term solar UV and ozone variations, not only using data taken at Japan and Brazil, but also at Chile.

\section{Introduction}

Solar ultraviolet (UV) radiations are generally categorized as three wavelength regions of UV-A $(315-400 \mathrm{~nm})$, UVB $(280-315 \mathrm{~nm})$, and UV-C (100 - $280 \mathrm{~nm})$. Such categorization is convenient to explain the relation between UV radiation observed from the ground and absorption due to ozone in the stratosphere. It is known that UV-C radiations give serious problems to our body. However, since ozone has large absorption cross-section throughout these wavelengths (largest around $260 \mathrm{~nm}$ ), UV-C radiations are completely absorbed in the stratosphere and never reach to the ground. Most of UV$B$ radiations, which give large damages to creatures, are also strongly absorbed by ozone, and only a small amount of UV-B can be observed from the ground. Therefore, intensity of UV-B radiation on the ground is very sensitive to the variation in total ozone amount along the line-of-sight. On the contrary, UV-A radiations are hardly absorbed by ozone and most of them can reach to the ground. UV-A radiations give relatively smaller damages to our body than other UV radiations.

The main objectives of the solar UV observations are as follows;

1. Monitoring long-term variation in solar UV (and differences depend on the local areas).

2. Confirmation of relationship between solar UV and ozone (for example, ozone hole).

\section{Biological effect caused by solar UV}

To confirm the differences in UV fluxes which depend on both time and local area, we set the same instruments at the middle latitude regions in both hemispheres, and have carried out long-term ground-based observations. We obtained some results at Ikebukuro and São Martinho that are concerned with ozone in the stratosphere. Although first two objectives can be partly accomplished, the third objective is beyond the scope of this paper. In this paper, we focused on the relationship between solar UV and ozone.

\section{Instruments and data}

We have used the radiometers and spectroradiometers manufactured by EKO Instrument Co., Ltd., Japan. The radiometers measure integrated solar UV fluxes using interference filters between 315 and $400 \mathrm{~nm}$ for UV-A, and between 280 and $315 \mathrm{~nm}$ for UV-B, respectively. The spectroradiometer measures spectrum of solar UV radiation between 295 and $400 \mathrm{~nm}$ using a diffraction grating with a wavelength resolution of $\sim 3 \mathrm{~nm}$. These instruments have field-of-views of $\sim 180^{\circ}$ and sensitivities with respect to the solar zenith angle $(Z)$ are negligible in the case of $Z<70^{\circ}$. Therefore, a tracking unit of a diurnal motion of the Sun is not necessary. They have been set at Rikkyo University $\left(35.7^{\circ} \mathrm{N}, 139.7^{\circ} \mathrm{E}\right)$, Ikebukuro, Tokyo, Japan, and the Southern Space Observatory of the National Institute for Space Research (INPE) in São Martinho $\left(29.4^{\circ} \mathrm{S}, 53.8^{\circ} \mathrm{W}\right)$, Santa Maria, Brazil. The main reason why we selected Brazil as another observational station is as follows; i) the middle latitude region in the southern hemisphere, ii) Brazil locates in the South Atlantic Anomaly (SAA) of the terrestrial magnetic field (surface magnetic field strength of the Earth is smallest around South America), iii) sometimes small fraction of so-called 'ozone hole' reaches above São Martinho.

According to Takeshita et al. (2001), the flux ratio of UV-B to UV-A becomes a good indicator of the stratospheric ozone amount. In the Southern Space Observatory at São Martinho, total ozone data measured with the Brewer-Dobson spectrometer have been available since 1992. On the contrary at Ikebukuro, although the total ozone amount has not been observed, the ozone data at Tsukuba $\left(36.0^{\circ} \mathrm{N}, 140.1^{\circ} \mathrm{E}\right)$ is available form the World Ozone and Ultraviolet Radiation Data Centre (WOUDC; Wardle et al., 1996). Tsukuba is about $50 \mathrm{~km}$ apart from Ikebukuro toward north-east. Both ozone data consist of one zenith ozone a day in Dobson Unit (DU).

In addition to Ikebukuro and São Martinho, radiometers (not spectroradiometers) have been set at Concepcion (University of Concepcion; $36.8^{\circ} \mathrm{S}, 73.1^{\circ} \mathrm{W}$ ) and Punta Arenas (University of Magallanes; $53.1^{\circ} \mathrm{S}, 71.0^{\circ} \mathrm{W}$ ), Chile (Makita et al., 2004). Since the latitude of Concepcion is similar to that of Ikebukuro, the data at Concepcion becomes good counterpart. During the spring season, ozone hole often extends to Punta Arenas (Salgado et al., 1996). It is suitable place to investigate the relationship between UV-B intensity and ozone hole. However, we do 
not have available ozone data at Chile that can be compared with solar UV data. Therefore, we do not show the UV data at Chile in this paper.

Data analysis has been done for the spectroradiometer in São Martinho and Ikebukuro, and the radiometers in Ikebukuro. These data have been taken since 2002. On the contrary, the radiometers in São Martinho had some problems in their operation between 2002 and 2003. Therefore, they were not used in this analysis. As daily UV data, 20 minutes averaged values around the local noon were used $\left(Z<<70^{\circ}\right)$. For the spectroradiometer data, we did not use the UV spectral information, but integrated fluxes of UV-A (315-400 nm) and UV-B (290$315 \mathrm{~nm})$. Wavelength coverage of UV-B region is somewhat different from the UV-B radiometer.

\section{Results}

Figure 1 shows spectroradiometer data at São Martinho between 2002 and 2004. Both UV-A and UV-B intensity shows seasonal variation with large variance due to weather condition (filled circle). To reduce the effect, UV$A$ variation during a day was used as an indicator of fine day. If UV-A variation of the day showed a smooth sinusoidal variation, we selected the data. As a result, we can obtain the envelope of seasonal variations (open circle). Under this selection rule, the envelope of UV-B variation is also acquired as shown in the lower panel of Figure 1. There can be seen difference in the relative amplitudes of seasonal variations for UV-A and UV-B. The amplitude of UV-A variation shows about a factor of 2 difference between summer and winter. On the other hand, that of UV-B reaches about a factor of 3 . This relatively smaller value of UV-B in winter season is due to the absorption by ozone. Larger solar zenith angle during winter season makes the effective ozone ( = zenith ozone $\times \sec Z$ ) larger. Relationship between UV-B flux and effective ozone becomes clearer when a flux ratio of UV$B$ to UV-A is used (Takeshita et al., 2001). Figure 2 shows a relationship between the ratio (UV-B/UV-A) and effective ozone at São Martinho. From our dataset, we can derive a similar exponential function with Takeshita's one as shown in the figure. They show clear anticorrelation with a correlation coefficient of -0.94 .

We can also derive similar exponential functions from the Ikebukuro spectroradiometer data using the ozone data observed at Tsukuba. Figure 3 shows the UV ratio of the spectroradiometer and effective ozone. The data clearly separated into two parts. The separation becomes clear, if they are divided into two periods, that is, before and after the maintenance period of the instrument in 2003. Although these two functions are different, both of them showed clear exponential relations between the ratio and effective ozone. From this result, it is probably clear that the Tsukuba ozone data can be used as an indicator of the Ikebukuro UV data. Anyway, we must calibrate the spectroradiometer output so that these two functions match each other.

On the other hand, results of the radiometers at Ikebukuro are quite complicated as shown in Figure 4. The distributions of data have larger scatter than previous two results. Generally, two radiometers for UV-A and UV-B work simultaneously at Ikebukuro. They all have small difference in output characteristics. The combination of radiometers is sometimes changed because of the maintenance period of the instrument. The UV ratio data in Figure 4 can be divided into, at least, 4 groups, that is, 4 types of instrumental combination are included in the figure. It is necessary to calibrate all radiometers using a certain standard instrument and the derived functions. All radiometers have overlapped observational periods with others.

All the derived functions had similar exponential relations. However, there are differences in each coefficient compared with the result of Takeshita et al. (dashed lines in Figures 2, 3, and 4). Takeshita et al. (2001) used a set of radiometers for observations at Syowa station, Antarctica. Since spectral responses of radiometer and spectroradiometer are different, it is natural that output signals become different each other, even if an input signals are the same. In addition, as mentioned in previous section, wavelength coverage in UV-B region is different each other. This is one of the reasons for the discrepancy between Takeshita's relation and ours. As for radiometers, the main reason for this discrepancy is the individual differences of radiometers.

\section{Summary and future works}

From the UV data observed at Ikebukuro and São Martinho, relation curves between the UV-B/UV-A and effective ozone are acquired. Ozone data at Tsukuba can also be used as a good indicator of UV data at Ikebukuro. Careful correction for a spectral response of the spectroradiometer at Ikebukuro and for individualities of the outputs of the radiometers both at Ikebukuro and São Martinho are going to be finished soon. It makes our data more reliable.

Using the long-term UV data and relation functions between the UV ratio and effective ozone, we can deduce ozone amount at Concepcion and Punta Arenas, and investigate following topics.

- $\quad$ Long-term variation of the solar UV flux depending on the local area.

- UV-B variation due to ozone hole in the southern hemisphere depending on the latitude.

- Relationship between SAA and UV flux.

To accomplish last two topics, some additional data with earth orbiting satellites (global mapping of ozone, highenergy precipitating particles, magnetic field, and so on) are necessary.

\section{Acknowledgements}

This work has been supported by Rikkyo University Frontier Project "Life's Adaptation Strategies to Environmental Changes". The authors thank students of the Federal University of Santa Maria (UFSM) for supporting our observations at the South Space Observatory in São Martinho. The ozone data at Tsukuba was downloaded from the World Ozone and Ultraviolet Radiation Data Centre (WOUDC). The authors give appreciation to WOUDC. 


\section{References}

Makita, K., M. Hoshino, M. Nishino, Y. Kato, M. Sato, M. Ejiri, H. Yamagishi, M. Ayukawa, M. Furukawa, R. Monreal, A. Foppiano, R. A. Guamieri, and N. J. Schuch, Ultra-Violet Rays and Imaging Riometer Observations at Punta Arenas, Chile, Bulletin of Science and Engineering Takusyoku Univ., Vol. 9, No. 1, pp13-18, 2004.

Salgado, C. C., V. W. J. H. Kirchhoff, Y. Sahai, V. Valderrama, and F. Zamorano, Ozone hole observations over Punta Arenas, Chile, ATMOSPHERIC OZONE, Proceedings of the XVII Quadrennial ozone symposium, 17-20, 1996.
Takeshita, S. H. Miyaoka, M. Ejiri, and M. Sasaki, Solar ultraviolet irradiance in the ozone hole region in Antarctica, Nankyoku Shiryo (Antarctic Record), Vol. 45, No. 1, pp 1-12, 2001.

Wardle. D. I., E. W. Hare, D. V. Barton, and C. T. McElroy, The World Ozone and Ultraviolet Radiation Data Centre -Content and Submission, ATMOSPHERIC OZONE, Proceedings of the XVII Quadrennial ozone symposium, 89-92, 1996.

UV-A at Sao martinho between Sep. 2002 and Dec. 2004

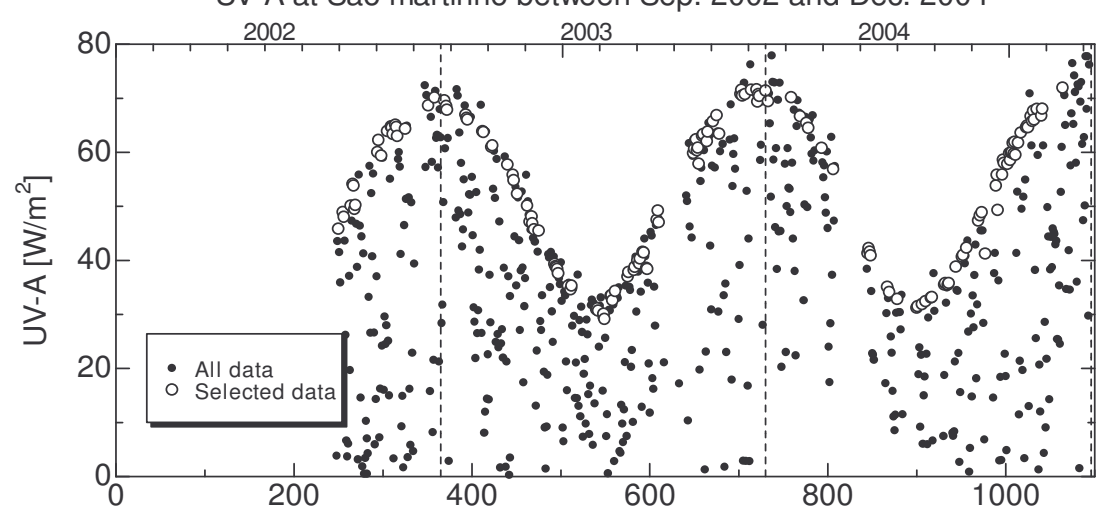

Day from 01 Jan. 2002

UV-B at Sao Martinho between Sep. 2002 and Dec. 2004

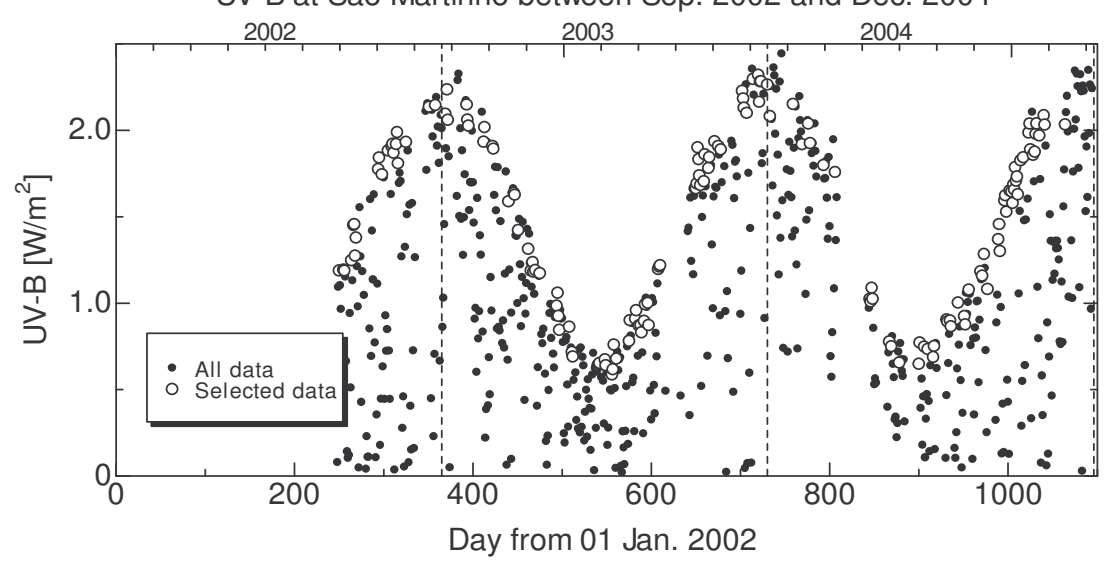

Figure 1: Seasonal variation of UV-A (upper) and UV-B (lower) radiations at São Martinho measured with the spectroradiometer between September 2002 and December 2004. Filled and open circles mean all data and selected data (fine day), respectively. The relative amplitudes of UV-A and UV-B variations showed differences mainly due to the absorption by ozone. 


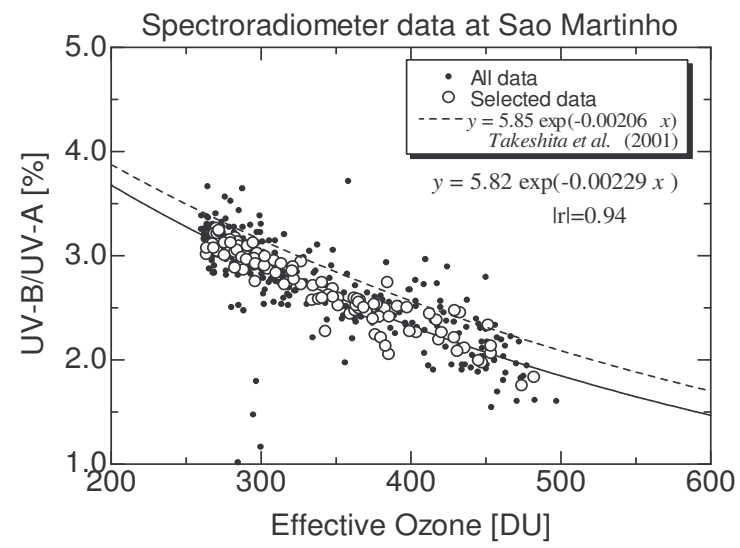

Figure 2: Flux ratio of UV-B to UV-A of the spectroradiometer at São Martinho with respect to effective ozone. Fitting result to the selected data (open circle) is shown as a solid line. Dashed line means a function of Takeshita et al. (2001).

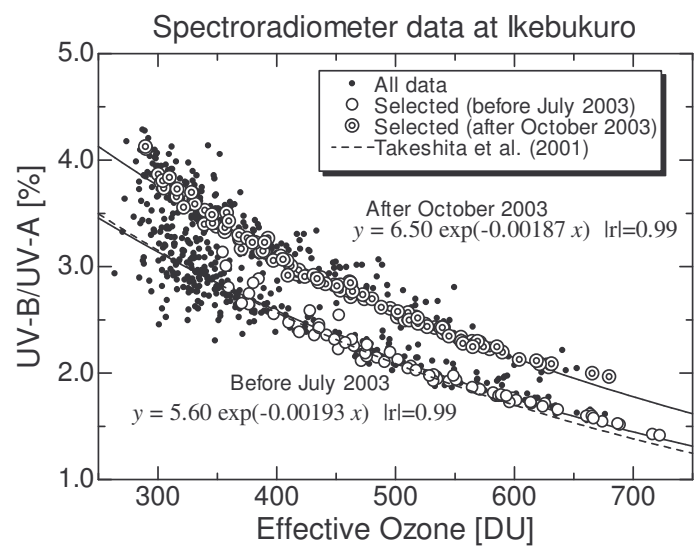

Figure 3: The UV ratio of the spectroradiometer at lkebukuro versus effective ozone evaluated from Tsukuba ozone data. Data points are separated into two parts. Dashed line means the result of Takeshita et al. (2001).

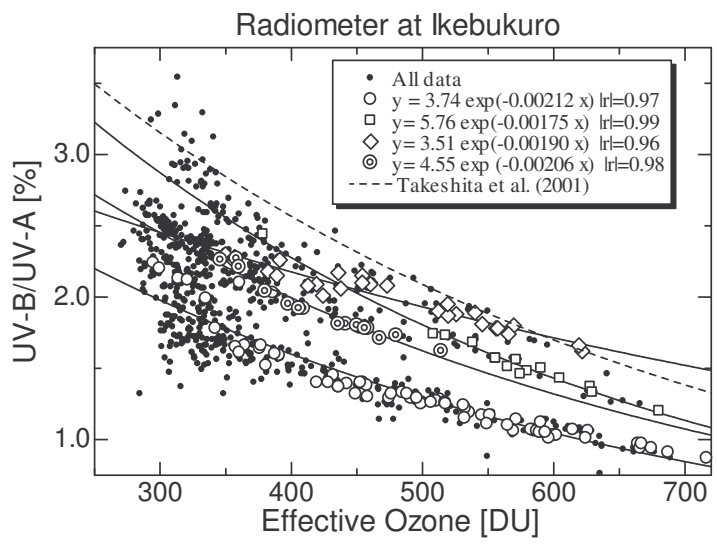

Figure 4: UV ratio of the radiometers at Ikebukuro versus effective ozone. The scatter of data is larger and four fitting results are obtained depending on the combinations of radiometers. 